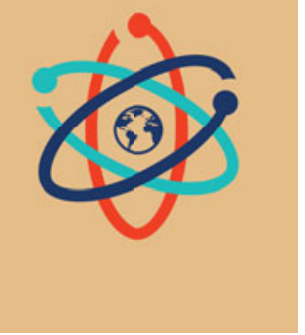

\title{
Materials researchers join historic March for Science
}

\author{
www.marchforscience.com
}

$T_{s}^{n}$ he historic, April 22nd March for Science in Washington, DC - with more than 600 satellite marches around the globe-focused the world's attention on the importance of science in daily life as it celebrated the work and achievements of the scientific community, including materials researchers.

March for Science organizers said, "We marched as an unprecedented coalition of organizations and individuals. We marched because science is critical to our health, economies, food security, and safety. We marched to defend the role of science in policy and society."

A cold rain came down most of the day in Washington, DC, but it

did not deter the esti-

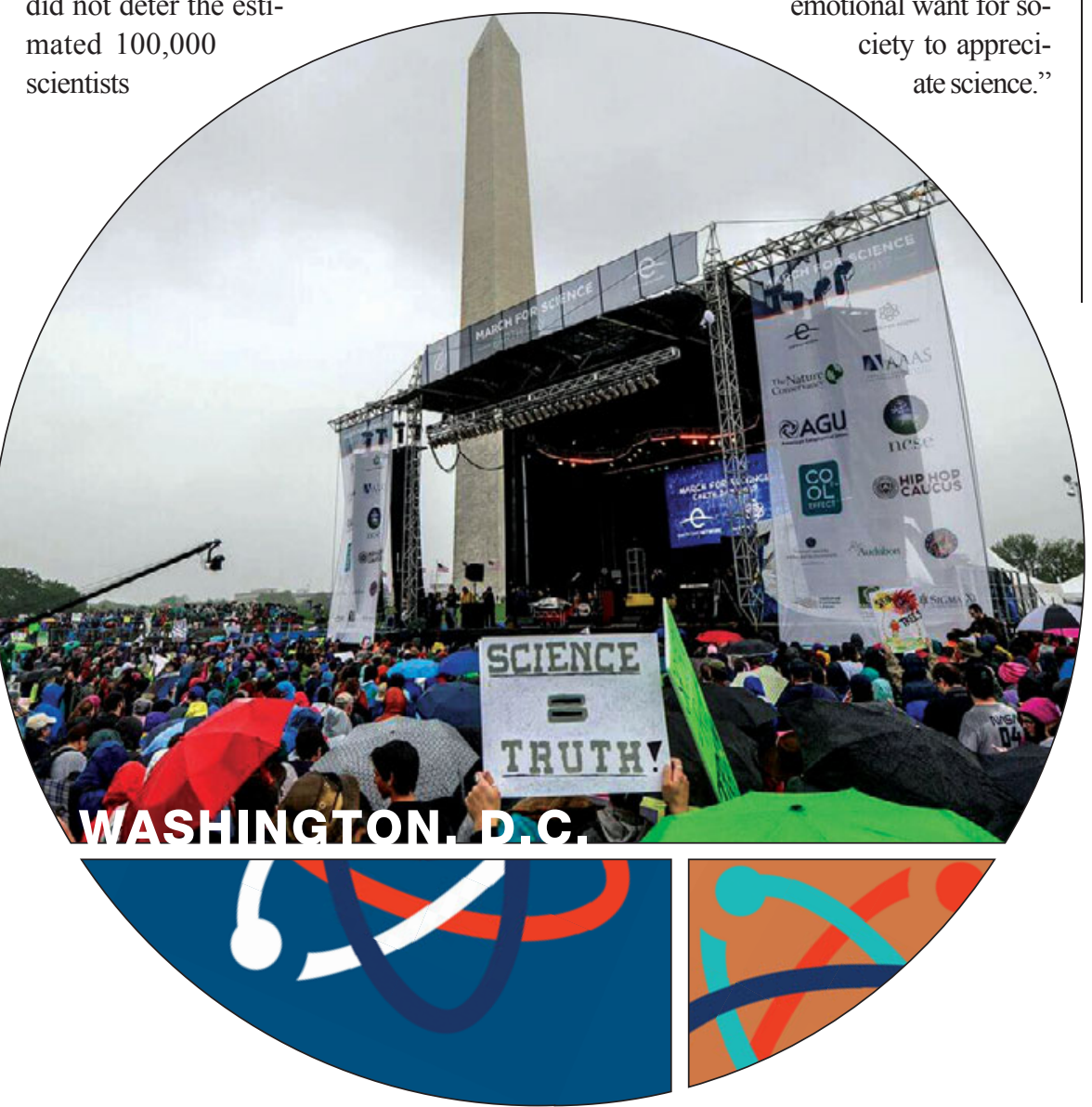

and their supporters who, starting at 8:00 am, huddled together in groups on the National Mall to enjoy a variety of music and the rally cries of scientists and their supporters onstage who kept the crowd fired up.

One materials scientist at the rally, Mindaugas Rackaitis, a research manager at Bridgestone Tire in Akron, Ohio, explained why he came to the March: "I disagree with the way the US government is treating science." He said he was particularly disturbed by recent actions such as the deletion of climate change information on the Environmental Protection Agency website.

For himself and other scientists, Rackaitis said, "there is this really emotional want for soto appreci-

\section{a} March, even though she was unable to stay beyond that for the festivities.

Leppert said she is concerned because "we are rapidly exceeding the planet's resources. It's clear we're going to need to innovate our way out of these constraints." And as a scientist, she feels it is important to provide the resources to train the next generation of scientists as well as provide the resources to support the work of science.

"We're lucky in this country to have this infrastructure that supports science in terms of the national user facilities," she said. "It's distressing to me to see the erosion in support for that effort in the last couple of decades," Leppert said, in terms of public funding for public universities and cutbacks at user facilities.

At another satellite march in Columbus, Ohio, materials researcher and MRS Fellow Len Brillson - a professor in the Departments of Electrical and 
Computer Engineering and Physics at The Ohio State University - said some 5600 people signed up for the Columbus March for Science, which took place on the square block lawn of the Ohio Statehouse.

Despite a chilly, overcast day, Brillson said, thousands of people filled the block from end to end.

"The mood of the crowd was festive with lively music, including Thomas Dolby's 'She Blinded Me with Science,"” he said.

Brillson said many marchers carried signs with slogans such as "Science Facts Not Alternative Science Fiction" or "Science, It Works!"

Speakers ranged from medical doctors covering the importance of vaccines and breakthrough medical advances to an ornithology professor who showed the importance of birds to the environment, Brillson said. "After the speeches, we all marched down High Street for several blocks to the Columbus Commons area where there was another rally."

Brillson said what he appreciated most about the day "was seeing so many thousands of Ohioans gathered together to support science."

Supporting science is the reason Joyce Wong, a professor of biomedical engineering at Boston University, joined the rally in Boston, "Science plays such an important role in our lives, but the lay public may not necessarily see the connections between science/engineering and their lives." Wong said it is important for scientists to tell "relatable stories" to show the public "why it is important to support science and not be afraid [of it]."

The March happened in tandem with celebrations of Earth Day, which began April 22, 1970, also in Washington, DC. Like the March for Science, said Earth Day Network - which is the sponsoring organization - that first celebration "activated 20 million Americans from all walks of life and is widely credited with launching the modern environmental movement."

Back in Washington, DC, the March for Science incorporated an Earth Day tradition of teach-ins about the environment and environmental concerns. Some incorporated materials research and themes.

At the Cool2Effect teach-in, for example, there were presentations about techn o 1 o g i c a 1 advances for preventing and mitigating carbon emissions. At an American Chemical Society children's demonstration, participants helped make colorful packing peanuts from corn starch instead of petrochemicals-literally, an often sticky, hands-on demonstration of the creativity and versatility in materials research today.

\section{Satellite marches around the globe}

Cities representing key hubs of materials research participated in the April 22nd event, from Boston to San Francisco, and Tokyo to London. And each city carried its unique message ranging from a humble support for science to outright protest against their current federal administrations.

\section{Boston}

Although the Boston event was rebranded as a "Rally for Science," traffic was still disrupted as thousands of supporters converged on Boston Common from satellite rallies at various universities and biomedical centers. The Boston Parks and Recreation Department said the city had at least 50,000 at the main stage area with upward of 70,000 when including the large children's section. Among the signs affirming the importance of science, climate change garnered the most expressions of concern; but other science topics were also visible, such as science's application to public health and enabling technology.
The official speeches largely advocated scientifically informed policies and federal funding for science. Gina McCarthy, former administrator for the Environmental Protection Agency, decried proposed large funding decreases for her former agency, as well as congressional moves that she said would disrupt scientific progress. Harvard Medical School geneticist George Church said he and his colleagues were "grateful and concerned" about funding for biomedical research in particular, where rapid changes increasingly require broad discussion and an informed population. Several invited speakers also advocated greater diversity in science-related fields, but few made a direct connection to immigration, which Church said enriches the scientific community.

Catherine Klapperich, a professor of biomedical engineering at Boston University, said she participated in the Boston rally with her twin daughters, age 9. "It was important for me to have them see that people in their community care about science and truth," she said. Klapperich has seen how the March and the spirited discussions surrounding it have profoundly impacted her graduate 
students. "They are much more in tune with how science is funded in the US, and much more aware of how changes in leadership can affect their future careers," Klapperich said. Now, beyond their interests in materials research, several students also want to participate in public policy. "This is new for me as a PI!"

Likewise, Wong at Boston University is impressed with her students' attention to public policy alongside their interest in biomedical engineering and biomaterials research. If funding of basic and advanced research is reduced, "we run the risk of losing a generation of scientists, including materials scientists and engineers," she said.

\section{Tokyo}

Bemused shoppers watched as a 100 -strong crowd of mostly foreigners made their way through the Ginza district on April 22nd for the Tokyo March for Science. Unlike its sister marches in Europe and the United States, the Tokyo March had no speeches or booths, but was peppered with rallying cries like "Yes the earth is getting hotter, money won't protect our water!" and "No science, no future!" The March lasted about 30 minutes.

Due to last-minute permit approval by the police, the Tokyo March was still a tentative affair one week before the scheduled date. The March also was not able to tie in with Earth Day events in the city's large Yoyogi Park, a traditional site for public gatherings. This may explain the limited publicity and modest turnout.

Alina Kudasheva, who just completed her $\mathrm{PhD}$ in composite materials research at the Tokyo Institute of Technology, said she would have attended had it not been for her recent move to a prefecture 250 miles outside the city. Kudasheva said she was not really aware of the impetus for the March, however: "I believe in science and whether the government is pro- or anti-science does not affect that, and currently, it also has no impact on my research activities." This kind of view may seem like a luxury to US researchers, but in Japan, science and technology are generally well regarded and there is no obvious bias against science in the country's legislative agenda.

Rich Bailey, one of the Tokyo organizers and faculty at a local university, speculated that Japanese scientists do not want to be perceived as advocates. Other than anti-nuclear activism, demonstrations also do not have a strong history in Japanese culture.

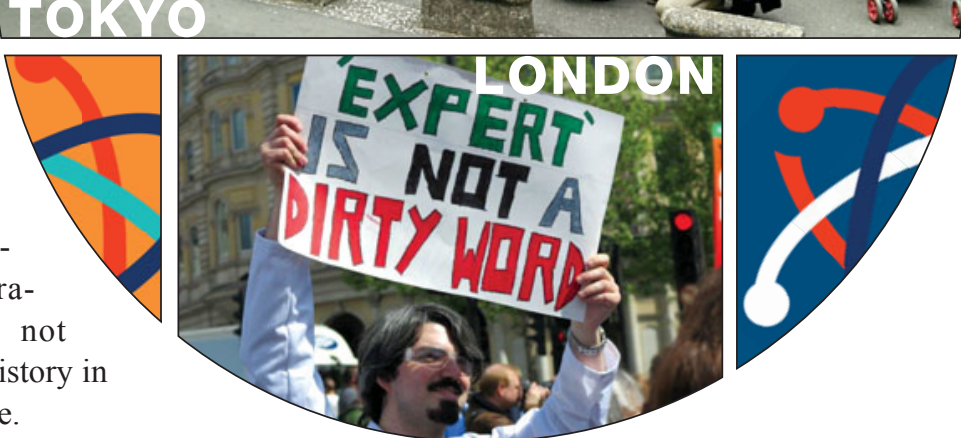

\section{San Francisco}

In stark contrast to Tokyo, numerous marchers in San Francisco said that support of science was a partisan issue and their message was strongly against the current presidential administration, with mantras such as "Make America think again" representing one chant on the milder side.

At a kickoff rally, Adam Savage, host of the television show MythBusters, warned the crowd against bias in science and policy. "Bias is very dangerous," he said. "It cannot only skew the results of a test, it can undermine our conclusions and our policies we make based upon those conclusions."

An estimated 15,000 people marched in the San Francisco March for Science, one of several such marches that took place in the science- and technology-rich San Francisco Bay Area on April 22nd. Protesters carried signs running the gamut from uplifting to angry, but many of them simply promoted basic respect for the scientific method. "Science is not a liberal conspiracy," read one sign. "I can't believe we have to do this," read another. The crowd marched peacefully through the heart of San Francisco, down Market Street to the Civic Center.
At the terminus of the march, protesters enjoyed a celebratory Science Fair and panels of speakers on topics like the future of science.

For many protesters, however, the issue was about more than just science. "I' $m$ here because facts are really important to me," said Dorit Grunberger, a former biochemistry researcher. "But it goes beyond that. It's about freedom of thought and respect for each other."

UC-Merced professor Leppert who, due to circumstances, participated in Phoenix instead of the Bay Area, also pointed out the significance of the support for science "as a proxy for the health of our democracy." She referred back to the founding of the country on the ideals of The Enlightenment of which "two of the core principles are rationality and scientific progress."

\section{London}

In the UK, the March also took more of a political turn. The looming pressure of Brexit, a clampdown on immigration affecting both researchers and students, and fears around climate change prompted thousands of protesters onto the streets of London. Buoyed 
by bursts of spring sunshine, the mood was positive. Marching from the Science Museum to Parliament Square, the participants chanted "Science, not silence!" and carried Earth-painted balloons.

"There is uncertainty surrounding the security of international collaborations and pots of money available from European research councils," said Suze Kundu, a materials chemist at Imperial College London, who was also one of the speakers at the rally. "As much as European collaborators would love to include us in projects, they are already saying that they are unsure as to whether they ought to, given that within the next two years that research may not be able to continue as it is now."

Paul Coxon, a materials scientist at the University of Cambridge, was part of a large delegation of Cambridge researchers at the March. "One major factor in the success of UK materials science and research has been our ability to attract and retain the very best international talent," he said. "It could become more difficult to recruit students and researchers to the UK in the future."

\section{Impact on public} opinion and policy

Alan Hurd, an executive advisor at Los Alamos National Laboratory in New Mexico, attended the March held in Santa Fe, which was also designed with speakers and science activities. When asked what made him decide to participate, Hurd was stunned, "I never really even thought I wouldn't!" This is unsurprising considering his experience with advocacy while serving as president of the Materials Research Society (2007) and, later, as a Franklin Fellow for the US Science and Technology advisor to the Secretary of State (2012-2013).

The term "March" signifies protest, Hurd said, which initially averted widespread support of the broad global science community. However, once the semantics were clarified and science organizations, including the Materials Research Society, understood the effort to be a partnership with the federal government to support the value of research, momentum quickly built up for the March, including the participation of policymakers.

Sealing that partnership Senator Tom Udall, addressing the March in Santa Fe, N.M., said, "I am excited to be here to honor scientists. I respect their intellect, their drive, their devotion to sci-

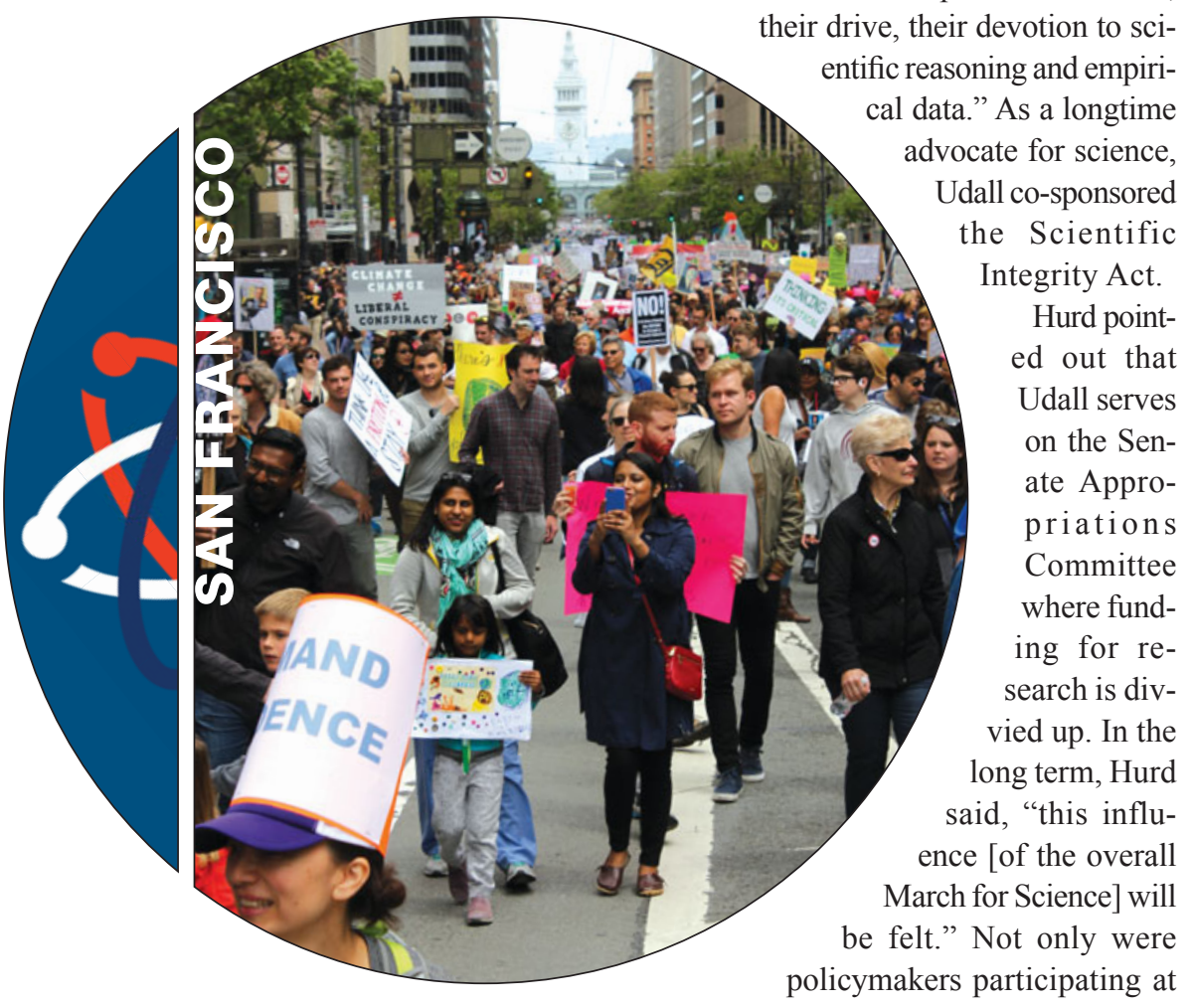

the numerous venues, but "scientists and students are hearing the clarion call to get politically active," Hurd said.

Wong (Boston) also sees this happening. "I am excited about how many of my colleagues are engaged in science advocacy," she said. Wong sees her colleagues participating in rallies, calling their congressional representatives and senators, speaking to congressional staffers, and working with scientific societies to educate staffers on the value of science.

Funding for materials research is particularly important, Wong said, "because materials are all around us and necessary for not only daily living but also in high-tech applications from vehicles for outer-space travel to medical devices."

In terms of the impact of the March on public opinion about science, Hurd said, "As a one-time event, the March will not move the needle in the US or the world. As an ongoing effort, maybe annually, it could have a substantial effect on the public depending on how it plays out."

March for Science organizers pledge that the historic event - which they calculated drew $\sim 1.07$ million marchers worldwide - will be an ongoing effort to support science and keep the public engaged about the importance of scientific research, building science literacy, and increasing science funding.

Hurd currently chairs ScienceCounts, a not-for-profit organization devoted to finding out how to reach the public about the value of science. When considering a 10-year-old child as an example, he said, "If [the March] becomes a part of Earth Day celebrations, it could have lasting effect."

Science writers Amanda Alvarez (@neuroamanda), Alison Hatt, Judy Meiksin (@Judy_Meiksin),Don Monroe, AngelaSaini (@AngelaDSaini), and William Schulz contributed to this report, with photography by Amanda Alvarez (Tokyo); Alison Hatt (San Francisco); Angela Saini (London); Boston University/Cydney Scott (Boston); and Earth Day Network, earthday.org (Washington, DC). 